\title{
Níveis nutricionais de treonina digestível para poedeiras comerciais durante o segundo ciclo de postura
}

\author{
Edwiney Sebastião Cupertino ${ }^{1}$, Paulo Cezar Gomes ${ }^{1}$, José Geraldo de Vargas Junior ${ }^{2}$, Luiz \\ Fernando Teixeira Albino ${ }^{1}$, Marlene Schmidtt ${ }^{1}$, Heloisa Helena de Carvalho Mello ${ }^{1}$
}

\footnotetext{
${ }^{1}$ Departamento de Zootecnia - Universidade Federal de Viçosa, Viçosa, MG.

2 Departamento de Zootecnia - Universidade Federal do Espírito Santo, Alegre, ES
}

RESUMO - Um experimento foi conduzido com o objetivo de estimar o nível ótimo de treonina digestível para poedeiras leves e semipesadas no segundo ciclo de postura. Foram utilizadas 360 aves, sendo 180 poedeiras leves e 180 poedeiras semipesadas, distribuídas em delineamento inteiramente casualizado, num arranjo fatorial $5 \times 2$ (5 níveis de treonina $\times 2$ linhagens de poedeiras). Os níveis de treonina digestível utilizados foram de 0,380;0,413;0,445; 0,478 e 0,511\%. Foram avaliados os dados de desempenho (produção, peso e massa de ovo), componentes dos ovos (albúmen, gema e casca), a qualidade interna dos ovos (unidades Haugh, índice de albúmen e de gema), percentual de ovos não comerciais e parâmetros de peso corporal. Pelos resultados obtidos, estimou-se para poedeiras leves nível de 0,446\% de treonina digestível, correspondendo a um consumo diário de $487 \mathrm{mg} /$ ave e relação treonina/lisina igual a 68, enquanto que para poedeiras semipesadas o nível estimado foi de $0,465 \%$ de treonina digestível, com consumo diário de $505 \mathrm{mg} /$ ave e relação treonina/lisina igual a 71 . Comparando a relação mg de treonina digestível por grama de ovo produzido, foram estimados valores de 9,5 e 10,0 mg de treonina/grama de ovo produzida.

Palavras-chave: desempenho, produção de ovos, relação de aminoácidos

\section{Nutritional requeriment of threonine digestible for laying hens during the second cycle of production}

\begin{abstract}
An experiment was carried out to estimate the optimum level of digestible threonine for white-egg and brown-egg laying hens in the second laying cycle. It was used 360 laying hens, 180 were white-egg and 180 were brownegg laying hens which were distributed in a complete randomized design in $5 \times 2$ factorial arrangement (5 levels threonine $\times 2$ lines of laying hens). The levels of digestible threonine used were the following: $0.380,0.413,0.445,0.478$ and $0.511 \%$. It was evaluated performance data (production, egg weight and mass), egg components (albumen, yolk and shell), egg internal quality (Haugh units, albumen and yolk indexes) and percentage of non-commercial eggs and body weight parameters. Through the obtained results, it was estimated for white-egg laying hens, levels of digestible threonine of $0.446 \%$, which matches a daily intake of $487 \mathrm{mg} / \mathrm{hens}$ and a lysine: threonine relationship equal to 68; for brown-egg laying hens, the estimate level of digestible threonine was $0.465 \%$ with a daily intake of $505 \mathrm{mg} / \mathrm{hens}$ and a lysine: threonine relationship of 71. By comparing the relationship mg digestible threonine per gram of produced eggs, values of 9.5 and 10.0 mg threonine/gram egg are estimate; gram of produced egg.
\end{abstract}

Key Words: amino acid relationship, egg production, performance

\section{Introdução}

As necessidades nutricionais de aminoácidos para poedeiras comerciais têm sido bastante pesquisadas, pois é prática comum calcular as dietas destas aves com base na recomendação de aminoácidos (Campos, 2001; Rocha et al., 2009), no padrão de proteína ideal, na digestibilidade dos aminoácidos e no custo de arraçoamento. De acordo com Faria et al. (2002) os resultados disponíveis na literatura, com referência aos níveis de treonina, são pouco consistentes, parecendo não haver concordância entre as recomendações. Esses níveis variam entre 0,423\% e 0,440\% (Valério et al., 2000) e 0,525 e $0,538 \%$ (Rostagno et al., 2005) para poedeiras leves e semipesadas, respectivamente. Valores estes que podem ter sido encontrados, pelos diferentes autores, devido às condições ambientais, nutricionais, genéticas e aos métodos utilizados nas determinações das necessidades nutricionais (Huyghebaert \& Butler, 1991). 
Em poedeiras comerciais, a deficiência de treonina afeta diretamente na resposta produtiva (Huyghebaert \& Butler, 1991; Ishibashi et al., 1998; Camps, 2001; Faria et al., 2002), uma vez que atua de forma efetiva no "turnover" proteico na mucosa intestinal (Novak et al., 2004). Além disso, participa da formação da proteína do ovo e da proteína muscular.

Outro aspecto a ser considerado é o custo das dietas. A treonina é o terceiro aminoácido limitante em rações à base de milho e farelo de soja (Sá et al., 2007), sendo, portanto, após a lisina e a metionina, o aminoácido a ser suplementado nas rações de poedeiras. Desta forma, a determinação dos níveis nutricionais de treonina digestível para alimentação de aves é necessária, principalmente em idades mais avançadas, uma vez que o uso das poedeiras por períodos maiores de produção faz com que a vida útil do animal seja prolongada.

Desta forma, o presente trabalho foi desenvolvido com o objetivo de determinar as necessidades nutricionais de treonina digestível para aves poedeiras leves e semipesadas no período de 54 a 70 semanas de idade.

\section{Material e Métodos}

O experimento foi realizado no setor de Avicultura do Departamento de Zootecnia do Centro de Ciências Agrárias da Universidade Federal de Viçosa.

Foram utilizadas 360 poedeiras de 54 semanas de idade, distribuídas em delineamento inteiramente ao acaso, em esquema fatorial $5 \times 2$, sendo cinco níveis de treonina digestível (0,380; 0,413; 0,445, 0,478 e 0,511\% de treonina digestível) e dois tipos de poedeiras: leves (Lohmann LSL) e semipesadas (Lohmann Brown), seis repetições e seis aves por unidade experimental. Apesar de ser esquema fatorial, e da possível ocorrência de interações significativas, foi determinado antes das análises estatísticas que o efeito dos diferentes níveis de treonina digestível seria decomposto para cada tipo de poedeira, de forma a estimar o nível nutricional para cada tipo de ave.

Uma ração basal foi formulada de forma a conter 13,07\% de PB, 2800 de EM/ kg de ração, 0,653\% de lisina digestível, 0,588\% de metionina + cistina digestível e 0,380\% de treonina digestível, segundo recomendações de Rostagno et al. (2000). A partir desta ração foram adicionados 0,$00 ; 0,036$, 0,$072 ; 0,108$ e $0,144 \%$ de L-treonina, de forma a obter os níveis de 0,380; 0,413; 0,445; 0,478 e 0,511\% de treonina digestível e a relação Tre:Lis digestível 58, 63, 68, 73 e 78\% (Tabela 1).

As suplementações com L-treonina (98\%) foram feitas em substituição ao aminoácido não essencial L-glutâmico e, quando necessário, foi acompanhada pela suplementação de amido e de outros aminoácidos essenciais, de modo a atender a relação mínima do aminoácido: lisina.

Para avaliação dos parâmetros produtivos utilizou-se um período experimental de 112 dias, distribuídos em quatro períodos de 28 dias, onde foram avaliados: consumo de ração, consumo de treonina, taxa de postura, peso médio dos ovos, massa de ovo, conversão alimentar (g de ração/g de ovo e kg de ração/dúzia de ovos), unidade Haugh, índice e peso de albúmen, índice e peso de gema, \% de casca, ovos comerciais e não comerciais. O consumo de ração foi obtido pela diferença entre a ração fornecida durante o período experimental e a sobra ao fim de cada período. O fornecimento de ração ocorria sempre as 7 e às 17 horas.

Na determinação do peso médio dos ovos e das características qualitativas, os ovos dos três últimos dias de cada período experimental, foram separados, identificados e pesados. Para tal, utilizou-se balança com precisão de $0,1 \mathrm{~g}$. Após a pesagem, procedeu-se a quebra dos ovos, para a medição da altura e peso de albúmen e de gema. Esses dados foram utilizados na determinação da unidade Haugh $\left(\mathrm{UH}=100 \log \left(\mathrm{H}+7,57-1,7 \mathrm{~W}^{0,37}\right)\right.$, no índice de albúmen (IA = altura do albúmen/média dos diâmetros do albúmen) e no índice de gema (IG = altura da gema/média dos diâmetros da gema), em que: $\mathrm{H}$ = altura do albúmen em mm e $\mathrm{W}$ = peso do ovo em $\mathrm{g}$.

A temperatura e a umidade relativa do galpão experimental foram verificadas duas vezes ao dia. Foram utilizados três termômetros de máxima e mínima e um termômetro de bulbo seco e de bulbo úmido. Estes termômetros foram distribuídos à altura das aves, de forma a representar melhor a umidade relativa e a temperatura junto à ave. O programa de luz utilizado foi de 16 horas (luz natural + luz artificial).

As análises estatísticas dos parâmetros avaliados foram realizadas por meio do programa SAEG - Sistema para Análises Estatísticas e Genéticas - UFV (1997).

As estimativas das exigências de treonina digestível foram estabelecidas com o uso de modelos quadráticos e/ou, "Linear Response Platou”, conforme ajustamento dos dados.

\section{Resultados e Discussão}

Observa-se que o consumo de ração de poedeiras semipesadas e o peso médio dos ovos de poedeiras leves e semipesadas não foram significativamente diferentes para os níveis de treonina estudados. Portanto, nem sempre o nível de treonina afeta os parâmetros produtivos de poedeiras comerciais (Tabela 2). Entretanto, o consumo de ração de poedeiras leves, a taxa de postura, a massa de ovos 
Tabela 1 - Composição das dietas experimentais

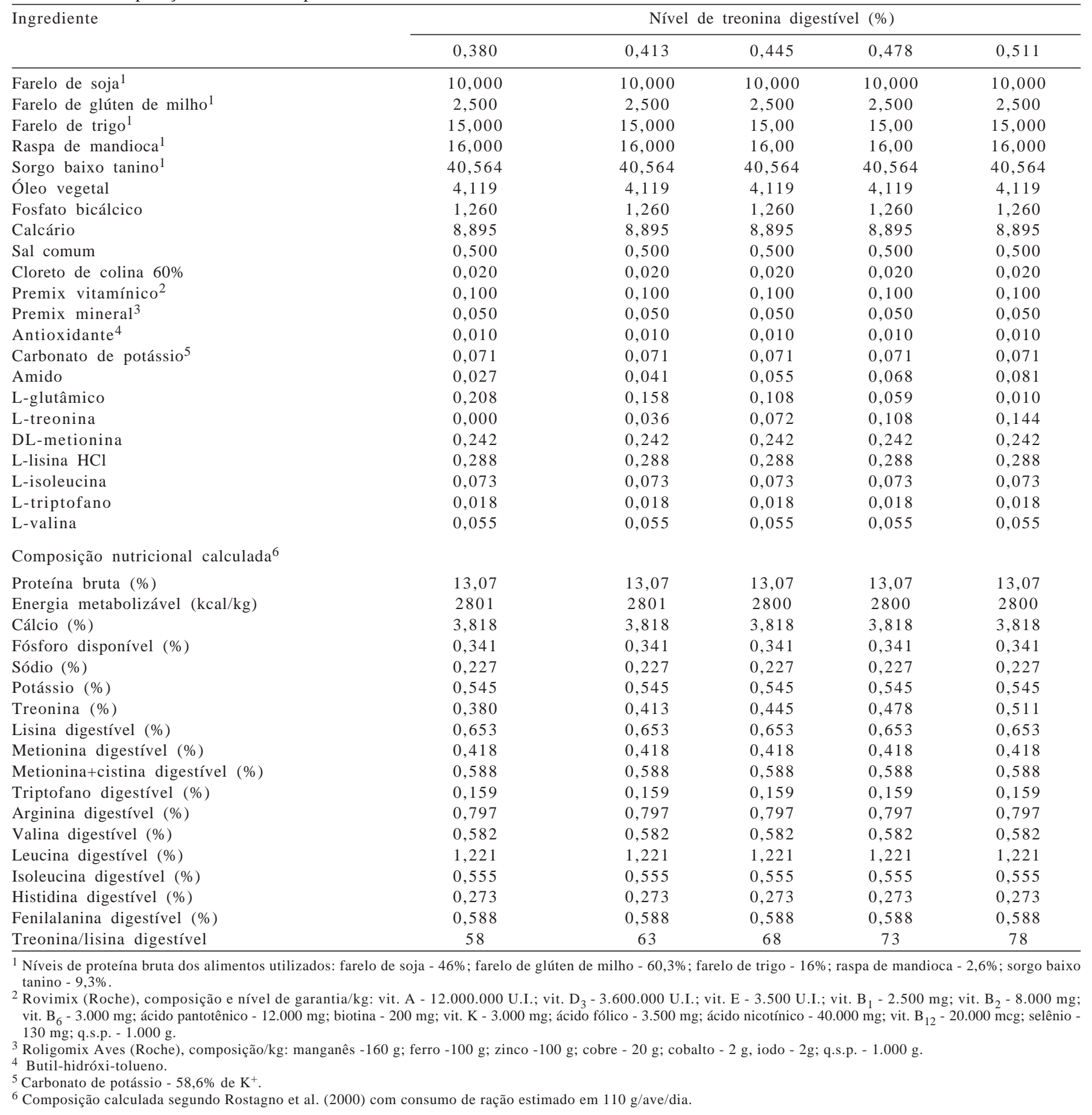

e o consumo de treonina foram afetados de forma significativa pelos níveis de treonina estudados.

Ao serem analisados os diferentes efeitos da treonina sobre o desempenho de poedeiras (Tabela 3), observa-se, para poedeiras leves, máximo consumo de ração, taxa de postura e massa de ovo, nos níveis de 0,444; 0,448 e 0,446\% de treonina digestível, correspondendo a consumo de 485 , 489 e $487 \mathrm{mg}$ de treonina digestível/ave/dia. Ao serem verificados os efeitos sobre poedeiras semipesadas, observa-se que a taxa de postura e a massa de ovos são aumentadas até os níveis de, respectivamente, 0,468 e 0,465\%, o que corresponde ao consumo de 508 e $505 \mathrm{mg}$ de treonina digestível/ave/dia.

Esses valores proporcionam relação lisina: treonina digestível de 68 e $71 \%$, respectivamente, para poedeiras leves e semipesadas. Estes valores são semelhantes aos observados por Amezcua et al. (1999), ao trabalhar com poedeiras semipesadas no período de 62 a 80 semanas de idade. 
Tabela 2 - Níveis de treonina digestíveis sobre parâmetros produtivos de poedeiras leves e semipesadas

\begin{tabular}{|c|c|c|c|c|c|c|c|c|c|}
\hline \multirow[t]{2}{*}{ Parâmetro } & \multirow[t]{2}{*}{ Tipo ave } & \multicolumn{5}{|c|}{ Nível de treonina digestível } & \multirow[t]{2}{*}{ Média } & \multirow[t]{2}{*}{ Efeito } & \multirow[t]{2}{*}{ CV $(\%)$} \\
\hline & & 0,380 & 0,413 & 0,445 & 0,478 & 0,511 & & & \\
\hline \multirow[t]{2}{*}{ Consumo de ração (g/ave/dia) } & Leves & 108 & 109 & 111 & 111 & 107 & $109,2 \mathrm{a}$ & $\mathrm{Q}^{*}$ & 3,54 \\
\hline & Semipesadas & 106 & 110 & 109 & 111 & 107 & $108,6 a$ & ns & \\
\hline \multirow{2}{*}{ Cons. de treonina(mg/ave/dia) } & Leves & 410,4 & 450,1 & 493,9 & 530,5 & 546,7 & $486,3 \mathrm{a}$ & $\mathrm{L} * *$ & 3,65 \\
\hline & Semipesadas & 402,8 & 454,3 & 485,0 & 530,5 & 546,7 & $483,8 \mathrm{a}$ & $\mathrm{L}^{* *}$ & \\
\hline \multirow[t]{2}{*}{ Taxa de postura (\%) } & Leves & 66,6 & 70,6 & 78,6 & 76,2 & 67,0 & $71,8 \mathrm{a}$ & $\mathrm{Q} * *$ & 6,78 \\
\hline & Semipesadas & 66,7 & 71,3 & 74,9 & 75,6 & 73,2 & $72,3 a$ & $\mathrm{Q}^{* *}$ & \\
\hline \multirow{2}{*}{ Peso médio dos ovos (g) } & Leves & 68,2 & 66,1 & 66,2 & 66,0 & 66,0 & $66,5 \mathrm{a}$ & ns & 2,80 \\
\hline & Semipesadas & 66,5 & 67,1 & 66,0 & 66,9 & 66,0 & $66,5 \mathrm{a}$ & ns & \\
\hline \multirow[t]{2}{*}{ Massa de ovo(g de ovo/ave/dia) } & Leves & 45,4 & 46,6 & 52,0 & 50,3 & 44,1 & $47,6 a$ & $\mathrm{Q} * *$ & 6,69 \\
\hline & Semipesadas & 44,3 & 47,8 & 49,4 & 50,6 & 48,3 & $48,0 \mathrm{a}$ & $\mathrm{Q}^{*}$ & \\
\hline
\end{tabular}

L - efeito linear, Q - efeito quadrático, CV - Coeficiente de variação, ** $(\mathrm{P}<0,01)$; $(\mathrm{P}<0,05)$; ns $(\mathrm{P}>0,05)$, médias seguidas por mesma letra entre tipos de ave, dentro do parâmetro avaliado, não diferem pelo teste F.

Faria et al. (2002), em trabalhos semelhantes, observaram que a necessidade diária de treonina total para poedeiras leves, no período de 45 a 52 semanas de idade, foi de 393 e 447 mg/ave/dia, para produção de ovos e massa de ovos, respectivamente. Ishibashi et al. (1998) estimaram necessidade de $457 \mathrm{mg} / \mathrm{ave} / \mathrm{dia}$, para massa de ovo, de aves com idade entre 29 e 39 semanas de idade.

Trabalhando com poedeiras semipesadas (Isa Brown) no período de 28 a 38 semanas de idade, Huyghebart \& Butler (1991) observaram que as aves alimentadas com 0,39\% de treonina na ração apresentaram menor taxa de postura (72,0\%) quando comparadas às aves alimentadas com $0,51 \%$ de treonina $(86,9 \%)$.

Ao ser feita uma relação entre consumo de treonina e diferentes parâmetros produtivos, observa-se diferentes níveis de ingestão de treonina em mg por ave dia. Ao relacionar esta ingestão de treonina com a massa de ovo, estimou-se consumo de 9,5 mg para aves leves e 10,0 mg para aves semipesadas para a produção de $1 \mathrm{~g}$ de ovo. Faria et al. (2002) estimam ser necessário consumo de 9,4 mg de treonina para se produzir $1 \mathrm{~g}$ de massa de ovo por poedeiras leves. Ao mesmo tempo, Rostagno et al. (2005) recomenda valores de 9,7 e 9,9 mg de treonina digestível, para poedeiras leves e semipesadas, respectivamente.
Em relação ao peso de ovo, não foi detectado efeito significativo $(\mathrm{P}<0,05)$ dos níveis de treonina digestível da dieta para os ovos de poedeiras leves e semipesadas, concordando com os resultados obtidos por Huyghebart \& Butler (1991), Ishibashi et al. (1998), Camps (2001), Faria et al. (2002) e Sá et al. (2007). Valério et al. (2000) relatam que poedeiras alimentadas com dietas contendo baixo teor proteico e suplementadas com aminoácidos essenciais têm apresentado bons resultados, mas não máximo desempenho.

Ao considerar os resultados para máxima produção de ovos, na avaliação da melhor relação treonina digestível/ lisina digestível, pode-se chegar aos valores de 68 e 71, respectivamente, para poedeiras leves e semipesadas. Recomendações essas bastante próximas do valor (70) obtido por Sá et al. (2007) para poedeiras leves e semipesadas.

Ao ser analisada a conversão alimentar ( $g$ de ração/g de ovos e kg de ração/dúzia de ovos) (Tabela 4), observa-se que os diferentes níveis de treonina digestível da dieta influenciaram de forma significativa os parâmetros avaliados. Sendo observado efeito quadrático $(\mathrm{P}<0,01)$ para ambos os tipos de conversão alimentar para poedeiras leves e efeito quadrático e linear, respectivamente, para conversão alimentar em g de ração/g de ovos e kg de ração/

Tabela 3 - Equações de predição ajustadas para as variáveis de desempenho de poedeiras

\begin{tabular}{|c|c|c|c|c|c|}
\hline \multirow[t]{2}{*}{ Parâmetro } & \multirow[t]{2}{*}{ Equação ajustada } & \multicolumn{2}{|c|}{ Exigência } & \multirow{2}{*}{$\begin{array}{l}\text { Relação } \\
\text { Tre:Lis }\end{array}$} & \multirow[t]{2}{*}{$\mathrm{r}^{2}$} \\
\hline & & $(\%)$ & (mg/ave/dia) & & \\
\hline \multicolumn{6}{|c|}{ Poedeiras leves } \\
\hline Consumo de ração (g) & $\hat{Y}=-0,05832+0,761081 X-0,8555 X^{2}$ & 0,444 & 485 & 68 & 0,73 \\
\hline Taxa de postura (\%) & $\hat{Y}=410,365+2171,42 X-2417,182 X^{2}$ & 0,448 & 489 & 68 & 0,86 \\
\hline Massa de ovo (g/ave/dia) & $\hat{Y}=-235,031+1280,92 X-1434,96 X^{2}$ & 0,446 & 487 & 68 & 0,77 \\
\hline \multicolumn{6}{|c|}{ Poedeiras semipesadas } \\
\hline Taxa de postura (g) & $\hat{Y}=168,367+1040,61 X-1110,55 X^{2}$ & 0,468 & 508 & 71 & 0,99 \\
\hline Massa de ovo (g/ave/dia) & $\hat{Y}=-119,619+729,004 X-782,425 X^{2}$ & 0,465 & 505 & 71 & 0,98 \\
\hline
\end{tabular}


Tabela 4 - Conversão alimentar de poedeiras leves e semipesadas alimentadas com dietas com diversos níveis de treonina digestível

\begin{tabular}{|c|c|c|c|c|}
\hline \multirow[t]{2}{*}{ Treonina digestível(\%) } & \multicolumn{2}{|c|}{ Conversão alimentar(g ração/g ovo) } & \multicolumn{2}{|c|}{ Conversão alimentar (kg ração/dúzia ovo) } \\
\hline & Leves & Semipesadas & Leves & Semipesadas \\
\hline 0,380 & 2,39 & 2,41 & 1,95 & 1,92 \\
\hline 0,413 & 2,37 & 2,30 & 1,87 & 1,86 \\
\hline 0,445 & 2,14 & 2,20 & 1,70 & 1,74 \\
\hline 0,478 & 2,22 & 2,20 & 1,76 & 1,76 \\
\hline 0,511 & 2,44 & 2,23 & 1,91 & 1,77 \\
\hline Média & $2,31 \mathrm{a}$ & $2,26 \mathrm{a}$ & $1,83 a$ & $1,81 \mathrm{a}$ \\
\hline Efeito & $\mathrm{Q} * *$ & $\mathrm{Q}^{*}$ & $\mathrm{Q}^{* *}$ & $\mathrm{~L} * *$ \\
\hline CV $(\%)$ & \multicolumn{2}{|c|}{6,14} & \multicolumn{2}{|c|}{6,23} \\
\hline
\end{tabular}

L - efeito linear, $\mathrm{Q}$ - efeito quadrático, CV - coeficiente de variação, ** $(\mathrm{P}<0,01)$; $(\mathrm{P}<0,05)$; ns $(\mathrm{P}>0,05)$, médias com mesma letra entre tipos de poedeiras, dentro do parâmetro avaliado, não diferem pelo teste $\mathrm{F}$.

dúzia de ovos, para poedeiras semipesadas. Huyghebaert \& Butler (1991), Yamazaki et al. (1997) e Ishiabashi et al. (1998) também encontraram efeito significativo dos níveis de treonina dietética sobre a melhoria da conversão alimentar. Por outro lado, Valério et al. (2000), testando níveis nutricionais de treonina para poedeiras leves e semipesadas, não observaram diferenças significativas.

As equações de determinação dos níveis de treonina para os tipos de conversão alimentar estudados (Tabela 5) estimam, para poedeiras leves, níveis de 0,451 e $0,446 \%$, que correspondem a consumo de 492 e $487 \mathrm{mg}$ de treonina digestível/ave/dia, respectivamente, para conversão alimentar g de ração/g de ovos e kg de ração/dúzia de ovos, num consumo de 109,2 g/ave/dia.

Para as poedeiras semipesadas foi encontrado nível de $0,472 \%$ de treonina digestível, equivalendo a consumo diário de 513 mg/ave, com um consumo de ração médio de 108,6 g/ave/dia, para variável conversão alimentar g de ração/g de ovo.

Os diferentes níveis de treonina digestível não afetaram de forma significativa a unidade Haugh, o índice de albúmen e o índice de gema de poedeiras leves e semipesadas. Resultados esses semelhantes aos obtidos por Valério et al. (2000). No entanto, comparando-se na média dos níveis de treonina estudados, foi observado que as poedeiras leves apresentaram valores de 87,$60 ; 0,1015 \mathrm{e}$ 0,4023, respectivamente, para unidade Haugh, índice de albúmen e índice de gema. Valores esses estatisticamente diferentes, pelo teste $\mathrm{F}$, dos obtidos por poedeiras semipesadas, que foram de 83,09; 0,0898 e 0,4406, respectivamente, para unidade Haugh, índice de albúmen e índice de gema.

Silversids \& Scott (2001) avaliaram o efeito de duas linhagens (Isa-White e Isa-Brown) sobre a qualidade dos ovos e concluíram que as poedeiras leves apresentaram maior altura de albúmen denso em relação aos ovos das poedeiras semipesadas. Valério et al. (2000) também perceberam que as poedeiras leves apresentaram valores superiores de unidades Haugh e índice de albúmen em relação às poedeiras semipesadas. Resultados esses confirmados por Sá et al. (2007).

Da mesma forma, comparando-se na média dos níveis de treonina estudados, foi observado que as poedeiras leves apresentaram valores de 41,3 g; 18,6 g; 9,57\% e 0,12\%, respectivamente, para peso de albúmen, peso de gema, porcentagem de casca e ovos não comercializáveis. Resultados esses estatisticamente diferentes, pelo teste $\mathrm{F}$, dos obtidos por poedeiras semipesadas que foram de 42,1 g; 17,8 g; 9,94\% e 1,24\%, respectivamente, para peso de albúmen, peso de gema, porcentagem de casca e ovos não comercializáveis. Estes resultados concordam com outros estudos simultâneos e provavelmente estas diferenças entre os componentes internos dos ovos das diversas linhagens possam ser de origem genética (Ahn et al., 1997;

Tabela 5 - Níveis de treonina digestível e coeficientes de determinação dos parâmetros avaliados

\begin{tabular}{|c|c|c|c|c|c|}
\hline Parâmetro & Equação ajustada & \multicolumn{2}{|c|}{ Exigência } & $\begin{array}{l}\text { Relação } \\
\text { Tre:Lis }\end{array}$ & $\mathrm{r}^{2}$ \\
\hline $\begin{array}{l}\text { Conversão alimentar (kg/dúzia) } \\
\text { Conversão alimentar (g/g) }\end{array}$ & $\begin{array}{c}\text { Poedeiras leves } \\
\hat{Y}=10,8837-40,5348 X+44,9050 X^{2} \\
\hat{Y}=12,4388-45,8750 X+51,3748 X^{2}\end{array}$ & $\begin{array}{l}0,451 \\
0,446\end{array}$ & $\begin{array}{l}492 \\
487\end{array}$ & $\begin{array}{l}69 \\
68\end{array}$ & $\begin{array}{l}0,85 \\
0,69\end{array}$ \\
\hline Conversão alimentar (g/g) & $\begin{array}{c}\text { Poedeiras semipesadas } \\
\hat{Y}=7,77328-23,6024 X+24,9622 X^{2}\end{array}$ & 0,472 & 513 & 72 & 0,99 \\
\hline
\end{tabular}


Tharrington et al., 1999), já que as alterações observadas são basicamente na relação gema/clara, não refletindo no peso do ovo.

O peso inicial de poedeiras leves e semipesadas e o peso final e variação de peso de poedeiras leves, não foram afetados pelos diferentes níveis de treonina digestível nas rações. Por outro lado, as poedeiras semipesadas apresentaram aumento do peso final à medida que foi sendo adicionado treonina digestível à ração. Do mesmo modo, nos menores níveis de treonina digestível, a variação de peso mostrou-se mais efetiva, ou seja, as aves apresentaram uma maior redução no peso corporal. Comparando-se na média os níveis de treonina, foi observado que as poedeiras leves apresentavam valores de 1673 g, 1479 g e - 194 g, respectivamente, para peso inicial, peso final e variação de peso. Resultados esses estatisticamente diferentes pelo teste $\mathrm{F}$, dos obtidos por poedeiras semipesadas, que foram de 1958 g, 1721 g e - 236 g, respectivamente para peso inicial, peso final e variação de peso. Observa-se assim que as poedeiras semipesadas tiveram uma maior perda de tecido corporal, que pode ser devido à maior mobilização de tecido corporal para atender a necessidade de mantença. Huyghebaest \& Butler (1991) também observaram perda de peso quando as aves poedeiras foram alimentadas com dietas contendo níveis reduzidos (menor que 0,40\%) de treonina na dieta.

A perda de peso corporal observada contraria as recomendações descritas nos manuais das linhagens e podem ter sido influenciadas pelos níveis de proteína bruta da dieta (13,0\%), conforme percebido por Pens \& Jensen (1991).

\section{Conclusões}

Recomendam-se valores de 0,446 e $0,465 \%$ de treonina digestível na dieta, que correspondem a 487 e $505 \mathrm{mg}$ de treonina digestível/ave/dia e 9,5 e 10,0 mg de treonina digestível/g de ovo produzida, gerando relação treonina:lisina de 68 e 71, respectivamente, para poedeiras leves e semipesadas no período de 50 a 70 semanas de idade.

\section{Referências}

AHN, D.U.; KIM, S.M.; SHU, H. effect of egg size and strain and age of hens on the solids content of chicken eggs. Poultry Science, v.76, p.914-919, 1997.

AMEZCUA, C.M.; LAPARRA VEGA, J.L.; AVILA GONZALES et al. Journal Applied Poultry Research, v. 8, p.236-241, 1999.

CAMPS, D.M. Dietas bajas en proteínas con suplementación de treonina y triptofano en la alimentación de ponedoras comerciales. Revista Cubana de Ciência Avícola, v.25, p.131-136, 2001.

FARIA, D.E.; HARMS, R.H.; RUSSEL, G.B. et al. Requerimiento de treonina de ponedoras comerciales alimentadas con una dieta de harina de maíz y trigo. Poultry Science, v.81, p.809-14, 2002.

HUYGHEBAERT, G.; BUTLER, E.A. Optimun threonine requirements of laying hens. British Poultry Science, v.32, p.575-582, 1991.

ISHIBASHI, T.; OGAWA, T.; ITO, S. et al. Threonine requirements of laying hens. Poultry Science, v.77, p.998-1002, 1998.

NOVAK C.; YAKOUT, H.; SCHEIDELER, S. The combined effects of dietary lysine and total sulfur amino acid level on egg production parameters and egg components in dekalb delta laying hens. Poultry Science, v.83, p.977-984, 2004.

ROCHA, T.C.; GOMES, P.C.; DONZELE, J.L. et al. Níveis de lisina digestível em rações para poedeiras no período de 24 a 40 semanas de idade. Revista Brasileira de Zootecnia, v.38, n.9, p.1726-1731, 2009.

ROSTAGNO, H.S.; ALBINO, L.F.T.; DONZELE, J.L. et al. Tabelas brasileiras para aves e suínos: composição de alimentos e exigências nutricionais. 1.ed. Viçosa, MG: 2000. 141p.

ROSTAGNO, H.S.; ALBINO, L.F.T.; DONZELE, J.L. et al. Tabelas brasileiras para aves e suínos: composição de alimentos e exigências nutricionais. 2.ed. Viçosa, MG: 2005. 186p.

SÁ, L.M.; GOMES, P.C.; CECON, P.R. et al. Exigência nutricional de treonina digestível para galinhas poedeiras no período de 34 a 50 semanas de idade. Revista Brasileira de Zootecnia, v.36, n.6, p.1846-1853, 2007.

SILVERSIDES, F.G., SCOTT, T.A. Effect of storage and layer age on quality of eggs from two lines of hens. Poultry Science, v.80, p.1240-1245, 2001.

THARRINGTON, J.B.; CURTIS P.A.; JONES, F.T. et al. Comparison of physical quality and composition of eggs from historic strains of single comb White Leghorn chickens. Poultry Science, v.78, p.591-594, 1999 .

UNIVERSIDADE FEDERAL DE VIÇOSA - UFV. Central de Processamento de Dados -UFV/CPD. SAEG - Sistema para Análises Estatísticas e Genéticas, versão 7.0 Viçosa, MG: Universidade Federal de Viçosa, 1997. 59p.

VALERIO, S.R.; SOARES, P.R.; ROSTAGNO, H.S. et al. Exigências nutricionais de treonina para poedeiras leves e semipesadas. Revista Brasileira de Zootecnia, v.29, n.2, p.518-524, 2000.

YAMAZAKI, M.H.; OHGUCHI, H.; MURAKAMI, M. et al. Available threonine requirement of laying hens. Japan Poultry Science, v.34, p.52-57, 1997. 